\title{
Examining the Role of Motivation and Learning Strategies in Student Success in Online Versus Face-to-Face Courses
}

\author{
Emily Stark \\ Minnesota State University, Mankato
}

\begin{abstract}
The goal of this paper is to compare the motivations and learning strategies of online and face-toface students, utilizing the Motivated Strategies for Learning Questionnaire (Pintrich et al., 1993). Prior research (Crede \& Phillips, 2011) suggests that motivation variables play a larger role in predicting student success in online courses compared to the specific learning strategies that are used, but little research has directly compared online students to face-to-face students. Results of this study found that while online students reported lower levels of motivation compared to faceto-face students, motivation variables were more strongly correlated with course performance than learning strategies, particularly for online courses. The results are discussed with implications for how to build student motivation to succeed, particularly in an online format, as well as different considerations for lower level or upper level students.
\end{abstract}

Keywords: online learning, learning strategies, motivation

Stark, E. (2019). Examining the role of motivation and learning strategies in student success in online versus face-to-face courses. Online Learning, 23(3), 234-251.

doi:10.24059/olj.v23i3.1556

\section{Author Note}

Please direct all correspondence regarding this article to Emily Stark at Dept. of Psychology, Minnesota State University, Mankato, 103 Armstrong Hall, Mankato, MN, 56001, USA. Contact by email at Emily.stark@mnsu.edu, phone at (507) 389-5822, or fax at (507) 3895831. 


\section{Examining the Role of Motivation and Learning Strategies in Student Success in Online Versus Face-to-Face Courses}

As online education continues to grow at a rapid pace (Seaman, Allen, \& Seaman, 2018), a growing number of studies have examined the characteristics of online learners. Much of this work has focused on both personal characteristics of these students (such as motivation, selfdiscipline, or self-efficacy) and their level of computer experience or access to technology, and has found that students' motivation and self-discipline predict success in online courses (Waschull 2005; Schrum \& Hong, 2002; Stark, Lassiter, \& Kuemper, 2013). However, it is unclear whether these predictors also equally apply to success in face-to-face courses or what aspects of motivation or particular study habits are facilitating student success. The goal of the current study is to examine whether taking a course online or face-to-face influences student motivation to succeed in that course, as well as to identify the strategies they employ to learn in that particular course, and how student motivations and learning strategies relate to course performance.

\section{Review of Literature}

Many students seek out online education because it offers them greater flexibility than face-to-face courses. In many online courses, students can choose to access learning materials and complete assignments on a schedule that is convenient for them, rather than attending class in a particular location or at a specific time. Although this flexibility can lead to increased rates of course withdrawal or failure for students who realize too late that they cannot manage their time effectively (Parker, 1999), other research has shown high rates of success in terms of course performance for students in online courses (del Valle \& Duffy, 2009), suggesting that most students are able to successfully adapt to an online environment.

The greater flexibility offered by online education has led researchers to focus primarily on characteristics related to self-discipline and motivation to understand how aspects of the learners influence their success in an online setting. For example, Cho and Shen (2013) found that intrinsic motivation and students' self-efficacy beliefs positively influenced both students' persistence and success in an online course. Specifically, students who reported stronger intrinsic motivation (as measured by learning itself being the primary goal, rather than only earning high grades) were more likely to use complex learning strategies, such as quizzing themselves after reading to test what they had learned, which then led to improved course performance. Similarly, Kerr, Rynearson, and Kerr (2006) found that motivation to learn, and ability to work independently through setting goals, being self-disciplined, and managing time, best predicted course success for online students, and Artino and Stephens (2009) found that higher levels of self-efficacy and belief that the course had value positively related to performance in online courses.

Other characteristics of students, such as their overall experience with college-level courses, may also influence their approach to online courses. Stark et al. (2013) found that motivation to study and self-discipline predicted higher course grades for upper level college students in an online course; for lower level college students, access to technology was the most significant predictor of online course success. It could be that students who have already developed successful study habits through experience with college courses can better apply them to an online course if they are motivated, whereas success for newer students is more dependent on basic access to technology. 
It may also be the case that student characteristics influence their decisions to complete online courses in the first place. Roblyer (1999) found that students who chose online courses placed a higher value on controlling the timing and pace of their learning, compared to those who chose face-to-face courses. Jenkins and Downs (2003) found no differences in age or gender when comparing online to face-to-face students; however, the online students were more likely to work full-time and live further from campus. These studies suggest that students chose online learning primarily for convenience and support the focus on examining student motivation as a predictor of success for online students.

The Motivated Strategies for Learning Questionnaire (MSLQ) was developed by Pintrich, Smith, Garcia, and McKeachie (1993) to assess types of academic motivation as well as strategies employed to assist in the learning of the material in a specific college course. This instrument is based on a social-cognitive view of the student, such that the specific context in which a student is learning will influence the particular motivations that arise in the student as well as the particular study approaches or learning strategies that the student employs (see Garcia \& McKeachie, 2005, for an overview of the MSLQ and review of research incorporating this tool). A student may be highly motivated to learn in a class for their major and willing to use time-intensive and complex study methods but less motivated to work as hard in a course that they see as less relevant to their future career goals.

The motivation scales for the MSLQ focus on three components (Pintrich et al., 1993): student beliefs that they can effectively complete tasks (self-efficacy), the reasons students engage with a course (including internal motivators, such as finding content interesting, or external motivators, such as striving to achieve high grades), and student anxiety over taking exams in a course. The learning strategies scales explore a range of approaches that students can use to manage their learning, ranging from simple and basic techniques, such as memorizing information, to more complex metacognitive approaches, such as reflecting on their own understanding or connecting material to other courses. Overall, this tool provides a range of potential motivation and learning variables that could both be influenced by the particular context of the course the student is taking and relevant to student performance in that course.

The focus of the MSLQ on student motivations and behaviors in a specific course (rather than in general) makes it a useful tool to examine how course modality, such as online versus faceto-face courses, influences student motivations to learn and the strategies they use to achieve learning, especially given that motivational variables have been shown in prior research to be particularly relevant to student success online. A growing number of studies have used the MSLQ to examine student performance specifically in online courses. For example, Castillo-Merino and Serradell-Lopez (2014) and Cho and Heron (2015) found that aspects of motivation played a stronger role in predicting student achievement compared to use of particular learning strategies; in these studies, motivational variables predicted course performance, but student effort or use of particular learning strategies did not relate to course grades nor, in Cho and Heron (2014), satisfaction with the course.

Cho and Heron (2014) suggest that the lack of relationship between course success and use of particular learning strategies was due to studying performance in a remedial mathematics course. For students in this study, being presented with mathematic problems and clear instructions to solve them, via the online system, perhaps did not leave them many options for using various types of learning strategies, making this aspect less relevant to their success in the course. Or, if students were mainly focused on passing the course and less concerned with earning high grades, 
they may have been less likely to put time into using more involved learning strategies in this particular course, doing only what was needed to pass. This suggests that the nature of specific courses can influence student motivations to succeed (i.e., being focused on passing the course rather than achieving high grades), which can then influence the specific techniques students use to learn course material.

Crede and Phillips (2011) conducted a meta-analysis of research utilizing the MSLQ, and found that the motivation constructs of self-efficacy and intrinsic motivation, as well as the overall strategies of spending more time studying and choosing appropriate study environments consistently predicted course grades. Intriguingly, the measures of complex learning strategies, such as using elaborative memory techniques versus rehearsing information, using critical thinking, or organizing material to be learned, did not regularly predict academic performance, even though these represent deeper and presumably more effective ways to learn material. Crede and Phillips (2011) encourage future researchers to more closely examine how course characteristics, such as the extent to which a course relies on multiple-choice exams, or the extent to which course content is complex and theoretical, may moderate students' use of learning strategies and their performance in the class.

Finally, Wang, Shannon, and Ross (2013) also used the MSLQ to examine students enrolled in online courses, and found that those who had taken online courses before reported using more learning strategies compared to those students new to online learning. Also, the use of more learning strategies led to increased motivation to learn, which then related to improved performance in online courses. The authors suggest that prior experience with online courses allows students to determine what strategies are most effective in that context, and that this experience increases students' technology self-efficacy and belief in their own abilities, leading to course success.

The goal of the current study is to extend this prior work by directly comparing the motivations and learning strategies of students in both online and face-to-face courses. Previous research has examined how these strategies and motivational variables relate to performance, but has not examined whether students enrolled in online classes report different motivations or approaches to learning the material compared to students enrolled in face-to-face classes. The population of students sampled for this current study attend a university with both online and faceto-face options for most courses, so students had the choice of format for their classes. This made for an ideal opportunity to study how the course context of being enrolled in online or face-to-face courses influenced both student motivations to learn and the strategies that they employed in that particular course. Thus, the following was my first research question:

- Research Question 1: Do students enrolled in an online course report different motivations or learning strategies for that course, compared to students enrolled in a face-to-face course?

This study also extends work examining the predictors of performance in online and faceto-face classes. Specifically, this study examined whether, as suggested by prior research (i.e., Cho \& Heron, 2015), motivational variables are more related to course performance for online compared to face-to-face courses. In addition, this study examined potential connections between particular motivations for success and the use of specific learning strategies. As such, my second and third research questions were the following: 
- Research Question 2: How do motivational and learning strategy variables predict performance in online compared to face-to-face courses?

- Research Question 3: Do specific motivational variables relate to use of particular learning strategies?

Finally, this study examined whether the strategies and motivations that best predict performance differ based on whether the students were lower level (i.e., self-reported as first years or sophomores) or upper level (reported themselves as juniors or seniors). Therefore, my final research question was the following:

- Research Question 4: Do motivational and learning strategy variables predict performance in online and face-to-face courses differently for lower level compared to upper level students?

There has been limited work addressing this question, so this will serve as an exploratory opportunity to begin to build an evidence base showing the impact of level of schooling on the connection between the MSLQ variables and course performance. Overall, this current study adds to an understanding of the learning strategies and motivations of college students in both face-toface and online courses, and how these relate to course performance.

\section{Setting}

\section{Methods}

This study was completed at the institution of the author, a midsize midwestern university in the United States, with a convenience sample of participants who were enrolled in psychology courses. Some participants were taking psychology courses as majors or minors in the department, whereas others were completing general education courses, such that a range of student majors and programs are represented in this sample. The research procedure and survey questions were approved by the university's Institutional Review Board before beginning data collection. All participants viewed consent information before beginning the survey, and all were given the opportunity to skip questions or quit the study at any time.

\section{Participants}

A total of 778 participants completed the survey (77\% female; $82 \%$ Caucasian/White). The average age of participants was 20.73 (range 18-53, SD =3.28). Participants also indicated their year in college, with $31 \%$ indicating they were first-year students, $17 \%$ sophomores, $19 \%$ juniors, and 25\% seniors, and 9\% noting "other," which could include non-degree-seeking students. Students' GPAs ranged from 1.15 to 4.00 , with an average of $3.29(S D=0.47)$, indicating fairly high achievement in courses among the participants. Students were asked to choose a particular class in which they were currently enrolled to consider as they completed the MSLQ, and then they noted whether that particular course was online or face-to-face. Responses were split fairly evenly, as $47 \%$ of participants responded thinking of an online course, and $53 \%$ responded thinking of a face-to-face course. Students were also asked to list the specific course that they referenced when responding to the MSLQ questions, and reported a wide range of courses across a number of majors and colleges at this university. Due to this range, specific details on the particular requirements or aspects of the online and face-to-face courses are not considered in this report. 


\section{Measures and Procedure}

The survey was disseminated using Qualtrics, an online survey tool. Participants first read consent information and then continued to the survey questions. The questions began with demographic information, including gender, age, year in school, race/ethnicity, and current GPA. Next, students were asked to indicate whether they were currently enrolled in a fully online course. They were told that for the remainder of the survey, they would need to answer the questions with a specific course in mind, and that if they were taking an online course, they should think of that course. If they were not currently enrolled in an online course, then they were told that they should pick one of their other current courses to think about as they responded to the survey questions.

The next portion of the survey included the 81 questions of the MSLQ (Pintrich et al., 1991). All 81 items were scored on a 7-point Likert scale, ranging from 1 (not at all true of me) to 7 (very true of me). Participants were instructed to think of the specific course they had noted previously, indicating how much they think each statement is true of them. See Appendix A for a list of all the items and specific scoring information.

The motivation scales include 31 total items, creating five overall measures of intrinsic motivation (focus on learning and curiosity about the subject matter: four items, $\alpha=.73$ ), extrinsic motivation (focus on earning high grades and approval from friends or family: four items, $\alpha=.64$ ), self-efficacy (a belief that they are able to learn the concepts taught in the class: eight items, $\alpha=$ .93), task value (how interesting, useful, or important the course content is perceived to be: six items, $\alpha=.92$ ), and test anxiety (worry about course exams: five items, $\alpha=.81$ ).

The learning strategy scales include 50 items, resulting in nine overall measures of various learning strategies. These include the simplest learning strategy of rehearsal of information (repeating items over and over to encourage memorization of concepts: four items, $\alpha=.73$ ), as well as more complex strategies of elaboration (summarizing information and connecting to other courses: six items, $\alpha=.80$ ), organization strategies (such as creating outlines or charts of course concepts: four items, $\alpha=.69$ ), critical thinking (evaluating evidence for theories or ideas presented in the course: five items, $\alpha=.77$ ), and metacognition (staying focused on learning and studying in a way to fit that particular course: 12 items, $\alpha=.78$ ). In addition, four scales measure strategies related to student resource management, including managing time and study environment (keeping up with assignments and studying regularly: eight items, $\alpha=.74$ ), regulating effort (working hard even if material is difficult or dull: four items, $\alpha=.66$ ), peer learning (studying with a friend: three items, $\alpha=.75$ ), and help seeking (asking for help if concepts are confusing: four items, $\alpha=.65$ ).

After responding to the MSLQ items, participants were asked to indicate their current grade in the course, with options of below $60 \%, 60-70 \%, 70-80 \%, 80-90 \%$, and above $90 \%$. Finally, participants were asked whether they were able to easily access the Internet for their studies. This was measured on a 5-point Likert scale, with endpoints of 1 (strongly disagree) and 5 (strongly agree). After completing this measure, participants were told they had completed the survey and were thanked for their participation.

Responses to all items were averaged to result in measures for the motivation and learning strategy scales, as described above. Independent samples $t$-tests were used to compare differences between students who responded to the scales thinking of a specific online course to those students who responded thinking of a face-to-face course. Regression analyses were used to examine how the motivation and learning strategy scales predicted self-reported course performance. These regressions were initially performed separately for participants from online and face-to-face 
courses, and then further separated to compare patterns of prediction for participants who reported being first years or sophomores and those who reported being juniors and seniors, in online or face-to-face courses.

\section{Results}

When comparing the motivations and specific learning strategies of students in online courses to those in face-to-face classes, independent samples $t$-tests showed significant differences for many of the measures. Due to the number of analyses, descriptive and inferential statistics comparing online to face-to-face students are presented in Table 1.

Specifically, students in online classes reported significantly lower levels of both intrinsic motivation and extrinsic motivation compared to students in face-to-face courses. The MSLQ conceptualizes intrinsic motivation as a focus on learning and mastery of the content, whereas extrinsic motivation refers to a goal of earning high grades or approval from others, so this finding suggests that students in the online courses were less motivated by both the content of the material itself and the potential to earn higher grades compared to those in face-to-face classes. Students also gave greater task-value ratings to face-to-face courses compared to online courses, showing that they viewed face-to-face courses as more interesting and useful. However, students had greater self-efficacy ratings for online courses compared to face-to-face courses, indicating that they felt more capable of success in online courses. There were no differences in reported test anxiety or their beliefs about the extent to which they could control their own learning between the two types of courses in this sample.

When comparing student learning strategies between online and face-to-face courses, several differences emerged. Students in face-to-face courses were more likely to report using the basic strategy of rehearsing information compared to those in online courses. Students in face-toface courses were also more likely to use the more complex strategy of organizing information while studying compared to those in online courses. Students in face-to-face classes also reported using more metacognitive strategies when studying compared to those in online courses. Finally, students in face-to-face courses reported greater usage of seeking peer support when learning and seeking help from the instructor compared to those in online courses.

Table 1

Differences in Reported Motivations and Learning Strategies Between Online and Face-to-Face Students

\begin{tabular}{llllllll} 
& & \multicolumn{3}{l}{$\begin{array}{l}\text { Online } \\
\text { courses }\end{array}$} & \multicolumn{2}{l}{$\begin{array}{l}\text { Cace-to-face } \\
\text { courses }\end{array}$} & \multicolumn{2}{l}{ Inferential statistics } \\
Variables & & $\boldsymbol{M}$ & $\boldsymbol{S D}$ & $\boldsymbol{M}$ & $\boldsymbol{S D}$ & $\boldsymbol{t}(\boldsymbol{d} \boldsymbol{f})$ & $\boldsymbol{p}$ \\
\hline Motivation & Intrinsic motivation & 4.61 & 1.19 & 4.89 & 1.08 & $-3.33(747)$ & $.001^{*}$ \\
variables & Extrinsic motivation & 5.50 & 1.06 & 5.67 & 0.98 & $-2.39(748)$ & $.017^{*}$ \\
& Task value & 4.88 & 1.49 & 5.39 & 1.26 & $-5.01(732)$ & $.0001^{*}$ \\
& Control of learning & 5.39 & 1.06 & 5.35 & 1.08 & $0.47(743)$ & .64 \\
& Self-efficacy & 5.48 & 1.13 & 5.20 & 1.18 & $3.38(737)$ & $.001^{*}$ \\
& Test anxiety & 4.14 & 1.43 & 4.25 & 1.41 & $-1.12(739)$ & .262 \\
& Rehearsal & 4.45 & 1.37 & 4.82 & 1.19 & $-3.95(745)$ & $.0001^{*}$ \\
& Elaboration & 4.67 & 1.21 & 4.79 & 1.09 & $-1.45(739)$ & .148
\end{tabular}




$\begin{array}{llllllll}\text { Learning } & \text { Organization } & 4.31 & 1.35 & 4.56 & 1.19 & -2.64(744) & .009 * \\ \text { strategy } & \text { Critical thinking } & 4.00 & 1.24 & 4.12 & 1.16 & -1.28(745) & .201 \\ \text { variables } & \text { Metacognition } & 4.34 & 0.92 & 4.48 & 0.84 & -2.19(734) & .029^{*} \\ & \begin{array}{l}\text { Regulating time/study } \\ \text { environment }\end{array} & 4.85 & 0.99 & 4.96 & 0.97 & -1.51(733) & .132 \\ & \begin{array}{llllll}\text { Regulating effort } \\ \text { Peer support }\end{array} & 5.13 & 1.13 & 5.15 & 1.07 & -0.24(745) & .809 \\ & 2.95 & 1.53 & 3.52 & 1.49 & -5.16(749) & .0001^{*} \\ & \begin{array}{l}\text { Seeking help } \\ \text { * significant difference }(p<.05) \text { between online and face-to-face courses }\end{array}\end{array}$

\section{Predicting Course Performance}

Students reported their current course grade based on their overall percentage grade. Only $1 \%$ of students reported course grades lower than $60 \%$, and many participants (44\%) reported course grades above $90 \%$. There was also a significant difference in reported grades based on the course modality; students reported higher grades in online courses $(M=4.34, S D=.90$, equivalent to $80-90 \%$ average) compared to face-to-face courses $(M=4.02, S D=.91$, equivalent to $70-80 \%$ average, $t(753)=4.96, p<.0001)$.

To predict course performance, regression analyses were performed separately for face-toface and online courses, including the motivation and learning strategy subscales as predictors. Only subscales that emerged as significant predictors of current course grades are reported in the text. See Table 2 for regression information for all variables.

Table 2

Predicting Course Performance in Online- and Face-to-Face Courses

\begin{tabular}{lllccc} 
& & Online & \multicolumn{3}{c}{ Face-to-face } \\
Variables & & $\begin{array}{c}\text { courses } \\
\text { courses }\end{array}$ & \multicolumn{1}{c}{$\boldsymbol{p}$} & $\boldsymbol{b}$ & $\boldsymbol{p}$ \\
\hline Motivation & Intrinsic motivation & -.119 & $.025^{*}$ & -.150 & $.015^{*}$ \\
variables & Extrinsic motivation & .049 & .283 & -.016 & .749 \\
& Task value & .009 & .816 & -.016 & .743 \\
& Control of learning & .048 & .324 & .003 & .958 \\
& Self-efficacy & .408 & $.0001^{*}$ & .513 & $.0001^{*}$ \\
& Test anxiety & -.069 & $.041^{*}$ & -.021 & .561 \\
\hline Learning strategy & Rehearsal & .017 & .696 & -.055 & .271 \\
variables & Elaboration & -.052 & .352 & .110 & .090 \\
& Organization & -.061 & .205 & .065 & .219 \\
& Critical thinking & .005 & .921 & .097 & .057 \\
& Metacognition & -.041 & .605 & -.215 & $.017^{*}$ \\
& Regulating time/study & .146 & $.017 *$ & .163 & $.012^{*}$ \\
& Environment & & & & \\
$* p<.05$ & Regulating effort & .008 & .882 & .012 & .847 \\
& Peer support & .008 & .842 & .046 & .237 \\
& Seeking help & .049 & .230 & -.014 & .737
\end{tabular}


For online courses, variables relating to motivation emerged as stronger predictors than variables relating to learning strategies. Specifically, students with lower intrinsic motivation $(b=$ $-.119, p<.025)$, lower test anxiety $(b=-.069, p<.041)$, and greater self-efficacy $(b=.408, p<$ $.0001)$ reported higher current course grades in their online course. Only the learning strategy variable of managing their time and study environment predicted current course grades for students in online courses $(b=.146, p<.017)$.

For face-to-face courses, variables relating to learning strategies played a slightly stronger role in predicting current course performance compared to the results for online courses. As with online courses, students with less intrinsic motivation $(b=-.15, p<.015)$ and greater self-efficacy $(b=.513, p<.0001)$ performed better in their face-to-face course. For learning strategy variables, students who reported less use of metacognitive strategies had higher grades $(b=-.215, p<.017)$, and students who reported more management of their time and study environment had higher grades $(b=.163, p<.012)$. Both critical thinking $(b=.097, p<.057)$ and elaboration $(b=.110, p$ $<.09)$ emerged as marginal predictors, such that students reporting greater use of these strategies had slightly better grades in their face-to-face class.

It was also predicted that students with greater motivation to succeed in their courses would use more complex learning strategies compared to students with lower levels of motivation. Results showed that both intrinsic and extrinsic motivation related positively and significantly to use of all the different learning strategies. Table 3 shows the correlation values for each.

\section{Table 3}

Correlations Between Intrinsic and Extrinsic Motivation Variables and Reported Use of Learning Strategies

$\begin{array}{lll}\text { Learning strategy } & \begin{array}{l}\text { Intrinsic motivation } \\ \text { Pearson correlation }(\boldsymbol{r})\end{array} & \begin{array}{l}\text { Motivation variables } \\ \text { Pearson correlation }(\boldsymbol{r})\end{array} \\ \text { Rehearsal } & .395^{* *} & .367^{* *} \\ \text { Elaboration } & .546^{* *} & .287^{* *} \\ \text { Organization } & .412^{* *} & .333^{* *} \\ \text { Critical thinking } & .490^{* *} & .240^{* *} \\ \text { Metacognition } & .530^{* *} & .336^{* *} \\ \text { Regulating time/study } & .283^{* *} & .298^{* *} \\ \text { environment } & & .221^{* *} \\ \text { Regulating effort } & .315^{* *} & .113^{* *} \\ \text { Peer support } & .265^{* *} & .122^{* *} \\ \text { Seeking help } & .173^{* *} & \\ * * p \text {-values }<.01 & & \end{array}$

To determine whether grade level (defined as lower level, meaning first or second year, or upper level, meaning third year or above) influenced the primary predictors of course performance, the prior regression analyses were performed again, now separately for lower level and upper level students.

For lower level students, the only significant predictor of success in an online course was extrinsic motivation $(b=.322, p<.013)$. None of the other motivation or learning strategy 
variables emerged as significant predictors. For lower level students in a face-to-face course, now only self-efficacy emerged as significant predictor of course success $(b=.543, p<.001)$.

The pattern of prediction was slightly different for upper level students. For upper level students taking an online course, intrinsic motivation $(b=-.228, p<.04)$, self-efficacy $(b=.567$, $p<.001)$, and organization $(b=-.234, p<.05)$ predicted success. It is important to note that both intrinsic motivation and organization negatively related to course grades, such that lower levels of intrinsic motivation and less reported use of organization predicted higher course grades for upper level students taking an online course.

For upper level students taking a face-to-face course, both intrinsic motivation $(b=-.428$, $p<.005)$ and self-efficacy $(b=.706, p<.001)$ were significant predictors of current course grades. Again, intrinsic motivation was a negative predictor, such that lower levels of intrinsic motivation related to higher course grades. See Table 4 for regression information for all variables.

Table 4

Predicting Course Performance for Lower Level and Upper Level Students

\begin{tabular}{|c|c|c|c|c|c|c|c|c|c|}
\hline & & Lowe & level st & dents & & Uppe & level si & udents & \\
\hline & & $\begin{array}{l}\text { Onlin } \\
\text { cours }\end{array}$ & & $\begin{array}{l}\text { Face- } \\
\text { cours }\end{array}$ & $\begin{array}{l}\text { o-face } \\
\text { s }\end{array}$ & $\begin{array}{l}\overline{\text { Onlin }} \\
\text { cours }\end{array}$ & & $\begin{array}{l}\text { Face- } \\
\text { cours }\end{array}$ & -face \\
\hline Variables & & $b$ & $p$ & $\boldsymbol{b}$ & $p$ & $b$ & $p$ & $\boldsymbol{b}$ & $p$ \\
\hline Motivation & Intrinsic Motivation & .013 & .927 & -.194 & .084 & -.161 & $.040 *$ & -.414 & $.005 *$ \\
\hline variables & Extrinsic motivation & .253 & $.013 *$ & -.123 & .151 & .009 & .888 & .114 & .249 \\
\hline & Task value & -.151 & .084 & -.054 & .566 & .053 & .353 & .181 & .095 \\
\hline & Control of learning & .114 & .297 & .059 & .514 & .054 & .468 & -.159 & .176 \\
\hline & Self-efficacy & .290 & .086 & .421 & $.001 *$ & .430 & $.001 *$ & .645 & $.001 *$ \\
\hline & Test anxiety & .080 & .449 & .002 & .975 & -.029 & .549 & .027 & .741 \\
\hline Learning & Rehearsal & .083 & .318 & .052 & .611 & .051 & .452 & -.197 & .117 \\
\hline strategy & Elaboration & .094 & .592 & .113 & .340 & -.053 & .489 & .167 & .274 \\
\hline variables & Organization & -.147 & .178 & .080 & .400 & -.140 & $.048^{*}$ & .060 & .626 \\
\hline & Critical thinking & -.087 & .370 & .119 & .205 & .044 & .530 & .151 & .195 \\
\hline & Metacognition & -.112 & .492 & -.248 & .148 & -.064 & .604 & -.282 & .171 \\
\hline & $\begin{array}{l}\text { Regulating time/ } \\
\text { study environment }\end{array}$ & .228 & .131 & .073 & .527 & .069 & .466 & .242 & .078 \\
\hline & Regulating effort & .085 & .594 & .141 & .183 & .065 & .407 & .025 & .864 \\
\hline & Peer support & -.102 & .250 & .056 & .431 & .051 & .379 & .091 & .353 \\
\hline & Seeking help & .090 & .347 & -.084 & .327 & .034 & .558 & -.049 & .614 \\
\hline
\end{tabular}

\section{Discussion}

First, this study examined differences between student learning strategies and motivations in online and face-to-face courses. Results showed that students in online courses had lower levels of both intrinsic and extrinsic motivation to succeed in that class and viewed their online course as less interesting and useful, compared to students in face-to-face courses. If students viewed their online courses as easier than their face-to-face ones, they could have needed less motivation or time to still do well in their courses. This interpretation is supported by the finding that students in online courses reported greater self-efficacy compared to those in face-to-face courses, such that 
they felt more able to successfully complete the work for those courses. Or, students in online courses could have felt more disconnected from the professor or other students due to the online format, and that could have reduced their motivation to engage in the course. It is important to note that students in online courses did report earning higher grades compared to those in face-to-face courses, so their success could be contributing to their perception of their courses as less difficult and therefore a lower motivation to succeed. However, this study did not measure students' perception of their courses, so it is difficult to understand why course format (online or face-toface) influenced their motivation.

Also, students in online courses reported less use of a number of learning strategies, including rehearsal, organization of information, metacognition, and seeking help from peers and the instructor, compared to those enrolled in face-to-face courses. Again, if students in online courses perceive or experience them as easier, they may be less likely to see the need to use specific learning strategies to enhance their performance. Of course, this study only asked students to reflect on one particular course, rather than comparing students who choose all online courses versus taking all face-to-face courses. Students who prefer to learn online could differ in meaningful ways from students who prefer to learn face-to-face, and future researchers should continue to examine the qualities of students who seek out this form of learning.

There were slight differences in the predictors of course grades when comparing online to face-to-face courses. The motivation variables did play a greater role in predicting success for online courses, whereas use of learning strategies related more strongly to performance for faceto-face classes. This is consistent with the reported low usage of learning strategies in general for online courses, such that these strategies do not seem relevant for success in the online environment, at least not for the students who participated in this study. Interestingly, students with less intrinsic motivation reported better grades for both online and face-to-face courses. It could be that being too focused on internal motivators may at times get in the way of studying information, and that students who are overly focused on mastering their understanding of the material (which is the primary way intrinsic motivation is conceptualized by the MSLQ) may run out of time to study the entirety of the material and miss components relevant to success on exams or papers. Or, if students are too focused on the external motivators for a class (i.e., grades), this could reduce their intrinsic motivation while still leading to a strong course performance (consistent with the undermining effect; see Eisenberger, Pierce, \& Cameron, 1999, for a discussion of the influence of incentives on intrinsic motivation). Basila (2014) also found that motivation negatively predicted success in an online course and noted that this could be due to the overall high grades that students earned in the online course, limiting the range of performance and hindering the study's ability to get an overall picture of the influence of motivation on course performance. Basila's (2014) study also utilized the MSLQ but analyzed all the motivation scales together, without identifying individual effects of intrinsic versus extrinsic motivation. Future researchers should spend more time examining the separate and combined effects of extrinsic and intrinsic motivations on student performance in a classroom, utilizing a broad sample with a full range of course performance scores.

As predicted, there was some relation overall between student motivation and the learning strategies used, such that students with greater intrinsic and extrinsic motivation were more likely to report using all of the learning strategies. This is consistent with the findings of Wang, Shannon, and Ross (2013), who also found positive correlations between motivations to learn and the use of learning strategies, as well as Kruger-Ross and Waters (2013), who found that students who 
perceived more value in the online course they were taking were more active at seeking out course information. Intrinsic motivation in particular related more strongly to use of the more complex learning strategies of elaboration, organization, critical thinking, and metacognition, compared to external motivation. Students who are driven to thoroughly master concepts (as internal motivation is defined by the MSLQ) seem to be more likely to put in the time to deeply think about the material, using the more complex learning strategies to learn and study. However, it is important to note that use of these more complex learning strategies did not necessarily lead to better course grades and that only the learning strategies of metacognition and regulating time related to earning a higher grade in the course. The use of more complex learning strategies by intrinsically motivated students could reflect them deepening their understanding of some of the course concepts rather than specifically pursuing better course grades overall.

Also, del Valle and Duffy (2009) examined different patterns of learning strategies used by students in an online course and found that while some students were more minimalist in their approach (spending less time) and others used more complex and time-intensive strategies, all students were successful in completing the course. Factors such as their past experience with both the subject matter and online learning in general influenced the approach that students took, and students were able to calibrate their effort and learning approaches to meet their specific course goals. The current study examines a wide range of course types as well as students with varying levels of online experience, familiarity with and interest in the subject matter, and other characteristics that all could be influencing their approach to learning in an online environment, which could lead to the lack of strong connections between specific learning strategies and course performance.

There were few differences in the patterns of prediction when comparing lower level students to upper level students. For lower level students, only extrinsic motivation predicted success in an online course, and only self-efficacy predicted success in face-to-face courses, and none of the learning strategy variables related to course success for either type of course. For upper level students, now intrinsic motivation negatively related to course success in both online and face-to-face courses, and self-efficacy positively related to success in both types of courses. For both lower and upper level students, the motivation variables were more relevant to course success than the learning strategy variables. Researchers should partner with course instructors to more deeply examine the class components that influence student motivations and the learning strategies students use and how these aspects influence student success in a course. For example, Chang et al. (2014) found that students with greater levels of Internet self-efficacy, or a belief that they could effectively learn in an online environment, showed stronger motivation to learn, which thereby improved their course performance. Both student experiences and aspects of the course itself could influence their motivation in an online setting, and these determinants should be explored in future research.

\section{Limitations}

In this study, students self-reported their current course grade, which could have led to errors or distortions. This study utilized a convenience sample as well, which limits the ability to generalize responses to students at other types of institutions, and could also have resulted in only certain types of students volunteering to complete the study. Specifically, self-reported grades were generally quite high among participants, as over half of participants reported course grades of $90 \%$ and above. This could be due either to students overstating their performance or to higher performing students being more likely to choose to participate in the study, and this limited 
variance in performance hinders an examination of how either their motivations or use of particular strategies affected their course grades.

Also, this research did not examine whether students had specifically chosen to take a course online or whether this was the only course option available to them. Both Mattes, Nanney, and Coussons-Read (2003) and Reisetter, Lapointe, and Korcuska (2007) found differences in the personality traits, past computer experience, and learning skills in students who chose an online course rather than a face-to-face course, and so student differences in preferred course modality could also be contributing both to their motivations to learn and their performance in a course. As students gain more options for online learning, future research should more closely examine distinctions between students who choose to learn online and those who do not have a choice in course format, to examine how student individual differences may be driving their learning strategies and motivations.

\section{Conclusion}

Overall, this study showed differences in the reported motivations and use of learning strategies between students in face-to-face and online courses, and it revealed some connections between different types of motivation and learning strategies and student performance in a course. Consistent with prior work (Crede \& Phillips, 2011; Cho \& Heron, 2015), the use of specific learning strategies did not strongly relate to student performance in their course. As the popularity of online courses and programs continues to rise, more attention should be paid to both the ways in which students approach and experience these courses and how student characteristics (such as motivation of different types) and activities (how they study and approach the material) relate to their success. 


\section{References}

Artino, A. R., \& Stephens, J. (2009). Beyond grades in online learning: Adaptive profiles of academic self-regulation among Naval Academy graduates. Journal of Advanced Academics, 20(4), 568-601. doi:10.1177/1932202X0902000402

Basila, C. (2014). Good time management and motivation level predict student academic success in college on-line courses. International Journal of Cyber Behavior, Psychology and Learning, 4(3), 45-52. doi:10.4018/ijcbpl.2014070104

Castillo-Merino, D., \& Serradell-Lopez, E. (2014). An analysis of the determinants of students' performance in e-learning. Computers in Human Behavior, 30, 476-484. doi:10.1016/j.chb.2013.06.020

Chang, C., Liu, E. Z., Sung, H., Lin, C., Chen, N., \& Cheng, S. (2014). Effects of online college student's Internet self-efficacy on learning motivation and performance. Innovations in Education and Teaching International, 51(4), 366-377. doi:10.1080/14703297.2013.771429

Cho, M., \& Heron, M. L. (2015). Self-regulated learning: The role of motivation, emotion, and use of learning strategies in students' learning experiences in a self-paced online mathematics course. Distance Education, 36(1), 80-99. doi:10.1080/01587919.2015.1019963

Cho, M., \& Shen, D. (2013). Self-regulation in online learning. Distance Education, 34(3), 290301. http://dx.doi.org/10.1080/01587919.2013.835770

Crede, M., \& Phillips, L. A. (2011). A meta-analytic review of the Motivated Strategies for Learning Questionnaire. Learning and Individual Differences, 21, 337-346.

del Valle, R., \& Duffy, T. M. (2009). Online learning: Learner characteristics and their approaches to managing learning. Instructional Science, 37, 129-149. doi:10.1007/x11251-007-9039-0

Eisenberger, R., Pierce, W. D., \& Cameron, J. (1999). Effects of reward on intrinsic motivation: Negative, neutral, and positive. Psychological Bulletin, 125, 677-691. doi:10.1037/00332909.125.6.677

Garcia Duncan, T., \& McKeachie, W. J. (2005). The making of the Motivated Strategies for Learning Questionnaire. Educational Psychologist, 40(2), 117-128. doi:10.1207/s15326985ep4002_6

Jenkins, S. J., \& Downs, E. (2003). Demographic, attitude, and personality differences reported by students enrolled in online versus traditional courses. Psychological Reports, 93, 213221.

Kerr, M. S., Rynearson, K., \& Kerr, M. C. (2006). Student characteristics for online learning success. Internet and Higher Education, 9, 91-105. doi:10.1016/j.iheduc.2006.03.002

Kruger-Ross, M. J., \& Waters, R. D. (2013). Predicting online learning success: Applying the situational theory of publics to the virtual classroom. Computers \& Education, 61, 176184. doi:10.1016/j.compedu.2012.09.015 
Mattes, C., Nanney, R. J., III, \& Coussons-Read, M. (2003). The online university: Who are its students and how are they unique? Journal of Educational Computing Research, 28(2), 89-102.

Parker, A. (1999). A study of variables that predict dropout from distance education. International Journal of Educational Technology, 1(2). Retrieved from http://smi.curtin.edu.au/ijet/v1n2/parker

Pintrich, P. R., Smith, D. A. F., Garcia, T., \& McKeachie, W. J. (1991). A manual for the use of the Motivated Strategies for Learning Questionnaire (MSLQ). Ann Arbor: University of Michigan, National Center for Research to Improve Postsecondary Teaching and Learning.

Pintrich, P. R., Smith, D. A. F., Garcia, T., \& McKeachie, W. J. (1993). Reliability and predictive validity of the Motivated Strategies for Learning Questionnaire (MSLQ). Educational and Psychological Measurement, 53, 801-813.

Reisetter, M., Lapointe, L., \& Korcuska, J. (2007). The impact of altered realities: Implications of online delivery for learners' interactions, expectations, and learning skills. International Journal on E-Learning, 6(1), 55-80.

Roblyer, M. D. (1999). Is choice important in distance learning? A study of student motives for taking Internet-based courses at the high school and community college levels. Journal of Research on Computing in Education, 32, 157-171.

Schrum, L., \& Hong, S. (2002). Dimensions and strategies for online success: Voices from experienced educators. Journal of Asynchronous Learning Networks, 6(1), 57-67.

Seaman, J. E., Allen, I. E., \& Seaman, J. (2018). Grade increase: Tracking distance education in the United States. Report of the Babson Survey Research Group.

Stark, E., Lassiter, A., \& Kuemper, A. (2013). A brief examination of predictors of e-learning success for novice and expert learners. Knowledge Management \& E-Learning, 5(3), 269-277.

Wang, C., Shannon, D. H., \& Ross, M. E. (2013). Students' characteristics, self-regulated learning, technology self-efficacy, and course outcomes in online learning. Distance Education, 34(3), 302-323. http://dx.doi.org/10.1080/01587919.2013.835779

Waschull, S. B. (2005). Predicting success in online psychology courses: Self-discipline and motivation. Teaching of Psychology, 32, 190-192. doi:10.1207/s15328023top3203_11 


\section{Appendix: Motivated Strategies for Learning Questionnaire}

Below are the individual items for the MSLQ. Please reference Pintrich, Smith, Garcie, and McKeachie (1991) for full details about subscales and scoring of this questionnaire.

\section{Section 1: Motivation}

1. In a class like this, I prefer new course material that really challenges me so I can learn new things.

2. If I study in appropriate ways, then I will be able to learn the material in this course.

3. When I take a test I think about how poorly I am doing compared with other students.

4. I think I will be able to use what I learn in this course in other courses.

5. I believe I will receive an excellent grade in this class.

6. I'm certain I can understand the most difficult material presented in the readings for this course.

7. Getting a good grade in this class is the most satisfying thing for me right now.

8. When I take a test I think about items on other parts of the test I can't answer.

9. It is my own fault if I don't learn the material in this course.

10. It is important for me to learn the course material in this class.

11. The most important thing for me right now is improving my overall grade point average, so my main concern in this class is getting a good grade.

12. I'm confident I can learn the basic concepts taught in this course.

13. If I can, I want to get better grades in this class than most of the other students.

14. When I take tests I think of the consequences of failing.

15. I'm confident I can understand the most complex material presented by the instructor in this course.

16. In a class like this, I prefer course material that arouses my curiosity, even if it is difficult to learn.

17. I am very interested in the content area of this course.

18. If I try hard enough, then I will understand the course material.

19. I have an uneasy, upset feeling when I take an exam.

20. I'm confident I can do an excellent job on the assignments and tests in this course.

21. I expect to do well in this class.

22. The most satisfying thing for me in this course is trying to understand the content as thoroughly as possible.

23. I think the course material in this class is useful for me to learn.

24. When I have the opportunity in this class, I choose course assignments that I can learn from even if they don't guarantee a good grade.

25. If I don't understand the course material, it is because I didn't try hard enough.

26. I like the subject matter of this course.

27 . Understanding the subject matter of this course is very important to me.

28. I feel my heart beating fast when I take an exam.

29. I'm certain I can master the skills being taught in this class.

30. I want to do well in this class because it is important to show my ability to my family, friends, employer, or others.

31. Considering the difficulty of this course, the teacher, and my skills, I think I'll do well in this class. 
Section 2: Learning Strategies

32. When I study the readings for this course, I outline the material to help me organize my thoughts.

33. During class time, I often miss important points because I'm thinking of other things. [reverse-coded]

34. When studying for this course, I often try to explain the material to a classmate or friend.

35. I usually study in a place where I can concentrate on my course work.

36. When reading for this course, I make up questions to help focus my reading.

37. I often feel so lazy or bored when I study for this class that I quit before I finish what I planned to do. [reverse-coded]

38. I often find myself questioning things I hear or read in this course to decide if I find them convincing.

39. When I study for this class, I practice saying the material to myself over and over.

40. Even if I have trouble learning the material in this class, I try to do the work on my own, without help from anyone. [reverse-coded]

41. When I become confused about something I'm reading for this class, I go back and try to figure it out.

42. When I study for this course, I go through the readings and my class notes and try to find the most important ideas.

43. I make good use of my study time for this course.

44. If course readings are difficult to understand, I change the way I read the material.

45. I try to work with other students from this class to complete the course assignments.

46. When studying for this course, I read my class notes and the course readings over and over again.

47. When a theory, interpretation, or conclusion is presented in class or in the readings, I try to decide if there is good supporting evidence.

48. I work hard to do well in this class even if I don't like what we are doing.

49. I make simple charts, diagrams, or tables to help me organize course material.

50. When studying for this course, I often set aside time to discuss course material with a group of students from the class.

51. I treat the course material as a starting point and try to develop my own ideas about it.

52. I find it hard to stick to a study schedule. [reverse-coded]

53. When I study for this class, I pull together information from different sources, such as lectures, readings, and discussions.

54. Before I study new course material thoroughly, I often skim it to see how it is organized.

55. I ask myself questions to make sure I understand the material I have been studying in this class.

56. I try to change the way I study in order to fit the course requirements and the instructor's teaching style.

57. I often find that I have been reading for this class but don't know what it was all about. [reverse-coded]

58. I ask the instructor to clarify concepts I don't understand well.

59. I memorize key words to remind me of important concepts in this class.

60 . When course work is difficult, I either give up or only study the easy parts. [reversecoded] 
61. I try to think through a topic and decide what I am supposed to learn from it rather than just reading it over when studying for this course.

62. I try to relate ideas in this subject to those in other courses whenever possible.

63. When I study for this course, I go over my class notes and make an outline of important concepts.

64. When reading for this class, I try to relate the material to what I already know

65 . I have a regular place set aside for studying.

66. I try to play around with ideas of my own related to what I am learning in this course.

67. When I study for this course, I write brief summaries of the main ideas from the readings and my class notes.

68. When I can't understand the material in this course, I ask another student in this class for help.

69. I try to understand the material in this class by making connections between the readings and the concepts from the lectures.

70. I make sure that I keep up with the weekly readings and assignments for this course.

71. Whenever I read or hear an assertion or conclusion in this class, I think about possible alternatives.

72. I make lists of important items for this course and memorize the lists.

73. I attend this class regularly.

74. Even when course materials are dull and uninteresting, I manage to keep working until I finish.

75. I try to identify students in this class whom I can ask for help if necessary.

76. When studying for this course I try to determine which concepts I don't understand well.

77. I often find that I don't spend very much time on this course because of other activities. [reverse-coded]

78. When I study for this class, I set goals for myself in order to direct my activities in each study period.

79. If I get confused taking notes in class, I make sure I sort it out afterwards.

80. I rarely find time to review my notes or readings before an exam. [reverse-coded]

81. I try to apply ideas from course readings in other class activities such as lecture and discussion. 